\title{
Nasal Carriage and Antimicrobial Susceptibility of Staphylococcus aureus in healthy preschool children in Ujjain, India
}

\author{
Ashish Pathak ${ }^{1,2^{*}}$, Yogyata Marothi ${ }^{3}$, Rama V lyer ${ }^{3}$, Binita Singh ${ }^{3}$, Megha Sharma $^{1,4}$, Bo Eriksson ${ }^{5}$, Ragini Macaden ${ }^{6}$, \\ Cecilia Stålsby Lundborg ${ }^{1}$
}

\begin{abstract}
Background: There is increasing evidence that community acquired S. aureus infections are spreading among healthy children. Nasal colonization with $\mathrm{S}$. aureus plays pivotal role in the increasing prevalence of resistant community acquired $S$. aureus infections worldwide. A regular surveillance system is important in ensuring quality of patient care. The aim of the study was to assess the prevalence of and the factors associated with nasal carriage of S. aureus and its antibiotic sensitivity pattern among healthy children in Ujjain, India.
\end{abstract}

Methods: A prospective study was done in paediatric outpatient clinics of R.D. Gardi medical college Ujjain, India. Healthy children from 1 month to 59 months of age were included. Information on previously known risk factors for nasal colonization was collected using a pre-tested questionnaire. Swabs from anterior nares were collected and transported in Amies transport media with charcoal and cultured on 5\% sheep blood agar. Antibiotic sensitivity tests were performed using Kirby Bauer's disc diffusion method according to performance standards of Clinical and Laboratory Standard Institute guidelines.

Results: Of the 1,562 children from 1-month up-to five years of age included in the study 98 children tested positive for nasal carriage of $S$. aureus. The prevalence of nasal carriage of S. aureus was $6.3 \%$ ( $95 \% \mathrm{Cl} 5.1-7.5)$ out of which 16.3\% (95\% Cl 8.9-23.8) were methicillin-resistant S. aureus (MRSA). The factors associated with nasal carriage were "child attending preschool" (OR 4.26, 95\% Cl 2.25-8.03; $P=0.007)$ or "school" (OR 3.02, 95\% Cl 1.27-7.18; $P<$ 0.001 ) and "family size more than 10 members" (OR $2.7695 \% \mathrm{Cl} 1.06-7.15 ; P=0.03$ ). The sensitivity pattern of isolated $S$. aureus showed resistance to commonly used oral antibiotics while resistance to glycopeptides was not noted.

Conclusions: We found a relatively low rate of nasal carriage of $S$. aureus in children below five years when compared to children of older age groups in India. Yet, prevalence of MRSA was relatively high.

\section{Background}

Staphylococcus aureus is a common pathogen responsible for community as well as hospital-associated infections. The infections caused by $S$. aureus have clinical range from minor skin infections to severe life threatening infections [1]. There is increasing evidence that community acquired methicillin-resistant $S$. aureus (CA-

\footnotetext{
* Correspondence: drashishp@rediffmail.com

'Division of Global Health (IHCAR), Department of Public Health Sciences,

Nobels väg 9, Karolinska Institutet, Stockholm, 17177, Sweden

Full list of author information is available at the end of the article
}

MRSA) is spreading among healthy individuals, especially children [2].

The anterior nares have been shown to be the main reservoir of $S$. aureus in both adults and children. The $S$. aureus is transmitted to nares by contaminated hands and from surfaces where it can survive for months [3]. Nasal carriage of $S$. aureus acts as endogenous reservoir for clinical infections in the colonized individual but also as a source of cross-colonization for community spread. The spread of colonization occur especially in close contact areas like schools, pre-schools or households [2] probably by the contaminated hands and surfaces.

\section{Biomed Central}

(c) 2010 Pathak et al; licensee BioMed Central Ltd. This is an Open Access article distributed under the terms of the Creative Commons Attribution License (http://creativecommons.org/licenses/by/2.0), which permits unrestricted use, distribution, and reproduction in any medium, provided the original work is properly cited. 
The individuals colonized with $S$. aureus (both CA-MRSA and CA-MSSA ie, community acquired methicillin-sensitive $S$. aureus) tend to have a complicated clinical course from a disease originating from their endogenous S. aureus [3]. The complicated clinical course results from increasing resistance in $S$. aureus isolates and also because the bacteria can cause deepseated infections and sepsis $[3,4]$. The difficulties in treating these deep-seated infections and sepsis require urgent measures to prevent further spread of MRSA. Setting up a bacterial surveillance system is one of the strategies to understand the epidemiology of MRSA to guide local antibiotic policy and to compare resistance patterns with other international surveillance systems. An improved understanding of epidemiology and resistance mechanisms of community acquired MRSA is required for designing better preventive strategies for further spread of resistance.

In India studies have been done in adults in intensive care units [5-8] and among patients at high risk of $S$. aureus infection [9] but studies on prevalence of nasal carriage and antibiotic susceptibility pattern of $S$. aureus in Indian children are few $[10,11]$. Further, prevalence studies in India have been done in children aged between 5 to 15 years of age but little is known about epidemiology of $S$. aureus in children below five years of age. Ramana et al [10] studied 392 children, aged 5 to 15 years and showed a carriage rate of $16 \%$ for $S$. aureus of which $19 \%$ were MRSA. Other Indian study by Chatterjee et al [11] using polymerase chain reaction (PCR) studied 489 children, aged 5 to 15 years and showed a prevalence of $52.5 \%$ for S. aureus of which $3.8 \%$ were MRSA.

The present study is done to understand the epidemiology of nasal carriage of S. aureus in view of paucity of studies in healthy children below five years of age in India. The first objective of the study was to estimate the prevalence of nasal carriage of S. aureus and MRSA as well as to identify factors associated with such carriage among healthy children (below 5 years of age). The second objective was to study the sensitivity patterns of the isolates.

\section{Methods}

This was a prospective study conducted during 15 months from November 2007 to February 2009.

\section{Study setting}

The study was conducted in paediatric outpatient clinics of two hospitals, the V.D. Gardi Charitable Trust Hospital (UCTH; the non-teaching hospital) and the C. R. Gardi Hospital (CRGH; the teaching hospital). UCTH is a 350 bedded hospital located in the city of Ujjain, whereas the 570 bedded CRGH is situated in a semi-urban area approximately six km from Ujjain city. C.R. Gardi Hospital is attached to R.D. Gardi Medical College (RDGMC). Both the hospitals cater to the population of Ujjain district, which has a population of 1,710,000 inhabitants with a population density of 281 per sq km [12]. Most hospital visits in both the hospitals are unscheduled visits from surrounding rural areas where agriculture is the main source of income.

\section{Study participants}

In the paediatric outpatients, healthy children from 1 month up-to 59 months of age visiting for routine immunization were included to identify nasal carriage of $S$. aureus. Children with any suspected infection including upper respiratory tract infection and those requiring admission or emergency care were not included. Also, patients with current skin infections were not included.

Parent or caregiver accompanying the child for immunization was interviewed by one of the study assistants and a questionnaire was filled-in. The questionnaire contained patient demographic characteristics and information on suspected factors associated with nasal carriage of $S$. aureus (for details see Table 1). A pilot study was done for one month (May 2007) each in both the hospitals using the questionnaire to test logistics and train the study assistants.

Verbal consent was obtained from all caregivers after explaining the purpose of the study. The ethics committee of R.D. Gardi Medical College approved the study (approval number 41/2007).

\section{Collection of nasal samples and laboratory methods}

Sampling for each participating child was performed by twice rotating a sterile cotton swab, pre-wetted with sterile saline in the vestibule of both anterior nares. The collected samples were transported in Amies transport media with charcoal (HiMedia, Mumbai, India) at a temperature between $4-8^{\circ} \mathrm{C}$ to the microbiology laboratory at R.D. Gardi Medical College, within 4 hours of collection.

Swabs were cultured on 5\% sheep blood agar, incubated at $35 \pm 1^{\circ} \mathrm{C}$ and examined for growth after 24-48 hours. Colonies growing on blood agar were identified as $S$. aureus by their typical colony morphology, Gram's staining, anaerobic utilization of glucose and mannitol, catalase production and tube coagulase test. Screening for methicillin resistance was done using cefoxitin disk screen test and $6 \mu \mathrm{g} / \mathrm{ml}$ of oxacillin in Mueller-Hinton agar supplemented with $\mathrm{NaCl}(4 \% \mathrm{w} / \mathrm{v} ; 0.68 \mathrm{~mol} / \mathrm{L})$ according to Clinical and Laboratory Standard Institute (CLSI) guidelines [13].

Antibiotic sensitivity tests were performed using Kirby Bauer's disc diffusion method according to performance 
Table 1 Multiple logistic regression analysist of factors associated with Staphylococcus aureus nasal carriage in children between 1 to 59 months of age in Ujjain

\begin{tabular}{|c|c|c|c|c|c|c|}
\hline \multirow[b]{2}{*}{ Factor } & \multirow[b]{2}{*}{ Totals ( $\%$ within column) } & \multicolumn{2}{|c|}{ Staphylococcus aureus } & \multirow[b]{2}{*}{$P$} & \multirow[b]{2}{*}{ Adjusted OR } & \multirow[b]{2}{*}{$95 \% \mathrm{Cl}$} \\
\hline & & $\begin{array}{l}\text { Positive } \\
\text { No. (\%) }\end{array}$ & $\begin{array}{l}\text { Negative } \\
\text { No. (\%) }\end{array}$ & & & \\
\hline \multicolumn{7}{|l|}{ Sex } \\
\hline Boy & $902(57.8)$ & $60(6.7)$ & $842(93.3)$ & 0.67 & 0.90 & $0.59-1.39$ \\
\hline Girl & $660(42.2)$ & $38(5.8)$ & $622(94.2)$ & & & \\
\hline \multicolumn{7}{|l|}{ Age group* } \\
\hline 1-6 months & $614(39.3)$ & $41(6.7)$ & $573(93.3)$ & 1 & 1 & - \\
\hline 7-12 months & $218(13.9)$ & $9(4.1)$ & $209(95.9)$ & 0.20 & 0.58 & $0.26-1.29$ \\
\hline 13-24 months & $248(15.8)$ & $12(4.9)$ & $236(95.1)$ & 0.16 & 0.56 & $0.25-1.26$ \\
\hline 25-59 months & $482(31.0)$ & $36(7.5)$ & $446(92.5)$ & 0.12 & 0.48 & $0.18-1.23$ \\
\hline \multicolumn{7}{|l|}{ Current breastfeeding status } \\
\hline Yes & $812(52.0)$ & $51(6.4)$ & $761(93.6)$ & 0.72 & 1.08 & $0.58-2.00$ \\
\hline No & $750(48.0)$ & $47(6.3)$ & $703(93.7)$ & & & \\
\hline \multicolumn{7}{|l|}{ Child attends* } \\
\hline No school & $1115(71.4)$ & $1062(95.2)$ & $53(4.8)$ & 1 & 1 & - \\
\hline Preschool & $143(9.2)$ & $123(86)$ & $20(14.0)$ & $<0.001$ & 4.26 & $2.25-8.03$ \\
\hline School & $304(19.4)$ & $279(91.8)$ & $25(8.2)$ & 0.012 & 3.02 & $1.27-7.18$ \\
\hline \multicolumn{7}{|l|}{ Family size* } \\
\hline Less than or equal to 4 & $449(28.7)$ & $21(4.7)$ & $428(95.3)$ & 1 & 1 & - \\
\hline Between 5-10 & $1061(68.0)$ & $70(6.7)$ & $991(93.3)$ & 0.12 & 1.50 & $0.89-2.54$ \\
\hline More than 10 & $52(3.3)$ & $7(13.5)$ & $45(86.5)$ & 0.03 & 2.76 & $1.06-7.15$ \\
\hline \multicolumn{7}{|l|}{ Education of the mother* } \\
\hline Illiterate & $593(38.0)$ & $26(4.4)$ & $567(95.6)$ & 1 & 1 & - \\
\hline Up-to primary & $537(34.2)$ & $44(8.2)$ & $491(91.8)$ & 0.10 & 1.65 & $0.90-3.03$ \\
\hline Up-to higher secondary & $255(16.3)$ & $20(8.2)$ & $235(91.8)$ & 0.24 & 1.51 & $0.74-3.07$ \\
\hline Graduate or post graduate & $179(11.5)$ & $8(4.5)$ & $171(95.3)$ & 0.95 & 1.02 & $0.42-2.51$ \\
\hline \multicolumn{7}{|l|}{ Occupation } \\
\hline Self employed & $990(63.4)$ & $52(5.2)$ & $938(94.8)$ & 0.33 & 0.77 & $0.45-1.29$ \\
\hline Salaried & $572(36.6)$ & $47(8.2)$ & $525(91.8)$ & & & \\
\hline \multicolumn{7}{|l|}{ Antibiotic usage in last 2 weeks } \\
\hline Yes & $330(26.8)$ & $25(7.6)$ & $305(92.4)$ & 0.92 & 0.97 & $0.60-1.57$ \\
\hline No & $1232(73.2)$ & $74(6)$ & $1158(94)$ & & & \\
\hline \multicolumn{7}{|l|}{ Hospitalization in the last 2 weeks } \\
\hline Yes & $137(8.8)$ & $17(12.4)$ & $120(87.6)$ & 0.08 & 1.79 & $0.92-3.47$ \\
\hline No & $1425(91.2)$ & $82(5.8)$ & $1343(94.2)$ & & & \\
\hline \multicolumn{7}{|l|}{ Hospital visit in the last 2 weeks } \\
\hline Yes & $370(23.7)$ & $31(8.4)$ & $339(91.6)$ & 0.25 & 1.32 & $0.81-2.14$ \\
\hline No & $1192(76.3)$ & $68(5.7)$ & $339(94.3)$ & & & \\
\hline
\end{tabular}

* Logistic regression was used with first value within variable acting as reference value.

${ }^{\dagger}$ A complete case analysis with $\mathrm{n}=1562$ was used. Variables entered: sex (boys versus girls), age group (13 months to 24 months and 13 to 24 months versus 1 12 months), current breastfeeding status (yes versus no), child attends no school, preschool, school (no school/preschool versus preschool and school), family size (between 5 to 10 members and more than 10 members to less than or equal to 4 members), education of the mother (up-to primary, up-to higher secondary and graduate or postgraduate versus illiterate), occupation of the breadwinner (self employed versus salaried), antibiotic use in the last 2 weeks (no versus yes), hospitalization in the last 2 weeks (no versus yes), hospital visit in the last 2 weeks (no versus yes).

standards of CLSI [13]. S. aureus ATCC 25923 was used as control strain. The panel of antibiotics tested included those that are recommended by CLSI or are commonly used locally in empirical treatment of $S$. aureus infections. The panel evolved after discussions with paediatricians and clinical microbiologists within and outside the research group. Susceptibility testing was done and results are presented for the following most important antibiotics: co-trimoxazole, ampicillin, coamoxiclav, ciprofloxacin, levofloxacin, ceftriaxone, erythromycin, clindamycin, doxycycline, chloramphenicol, tetracycline, gentamicin, amikacin, linezolid, teicoplanin and vancomycin. Inducible clindamycin resistance was detected by double disk diffusion test ( $\mathrm{D}$ test); 
performed by placing the clindamycin and erythromycin disks $15 \mathrm{~mm}$ apart [14]. For both MSSA and MRSA we defined multi-drug resistant (MDR) isolates as those resistant to 3 different antibiotics ie, co-trimoxazole, ciprofloxacin and erythromycin.

\section{Statistical analysis}

The data was entered in EpiData Entry (version 3.1) and then transferred to Stata 10.0 (Stata Corp. College Station, Texas, USA) software for statistical analysis. Prevalence of S.aureus and MRSA were estimated with $95 \%$ confidence intervals. The relationship between each variable and the outcome (nasal carriage of S. aureus) was explored using odds ratios (OR). Crude OR's were calculated from two by two tables. A given variable was entered in the final multiple logistic model if the bivariate analysis yielded a $\mathrm{P}$ value less than 0.1. All the variables were adjusted for age and sex. A complete case series analysis was used. The independent variables included were: sex (boys versus girls), age group (7 to 12 months, 13 to 24 months and 25 to 59 months versus 1 to 6 months), current breastfeeding status (yes versus no), child attends no school, preschool, school (no school/no preschool versus preschool, school), family size (between 5 to 10 members and more than 10 members to less than or equal to 4 members), education of the mother (up-to primary, up-to higher secondary and graduate or postgraduate versus illiterate), occupation of the breadwinner (self employed versus salaried), antibiotic use in the last 2 weeks (yes versus no), hospitalization in the last 2 weeks (yes versus no), hospital visit in the last 2 weeks (yes versus no). Chi-square tests were used to test for statistical significance (5\%).

\section{Results}

\section{Study population}

Of the 1600 caregivers approached 1,562 (98\%) consented for their child to participate in the study; 902 were boys (58\%) and 660 girls (42\%). Almost equal numbers of children were enrolled from the two hospitals. Thirty-nine percent of the children were between 1 and 6 months of age, 31\% were between 25 and 59 months.

The prevalence of breastfeeding before 6 months of age was $92 \%$; however whether breastfeeding was exclusive or not was not documented. About $50 \%$ of the 482 children above 3 years of age went to school or preschool and $9 \%$ to $17 \%$ of children in the different age categories utilized anganwadi which are Government of India run mother and child care services (pre-school) intended for children between 0 to 6 years of age.

Thirty-eight percent of mothers were uneducated or educated with only primary education. Most of the mothers $(84 \%)$ with graduate or postgraduate degree were enrolled from the non-teaching whereas $64 \%$ of all illiterate mothers were enrolled from the teaching hospital.

Antibiotic usage in the last 2 weeks was reported for $26 \%$ of children. A history of hospital visit other than for immunization in the last 2 weeks was noted for $27 \%$ of all children and $8.7 \%$ had a history of hospitalization in the last 2 weeks (Table 1).

\section{Factors associated with nasal carriage}

The prevalence of nasal carriage of S. aureus was $6.3 \%$ (95\% CI 5.07-7.47). Out of 98 S. aureus isolates $16.3 \%$ (95\% CI 8.87-23.77) were MRSA. The factors associated with colonization with $S$. aureus are shown in Table 1. The statistically significant OR observed in the multiple logistic regression models with nasal carriage of $S$. aureus as dependent variable were "child attending preschool" (OR 4.26, 95\% CI 2.25-8.03; $P=0.007$ ) or "school" (OR 3.02, 95\% CI 1.27-7.18; $P<0.001$ ) and "family size more than 10 members" (OR 2.76 95\% CI 1.06-7.15; $P=0.03$ ).

\section{Antibiotic sensitivity pattern}

The in-vitro antibiotic sensitivity pattern of 82 isolates of methicillin susceptible $S$. aureus (MSSA) is shown in Figure 1. Resistance to commonly used oral antibiotics, ampicillin (90\%), co-amoxiclav (54\%), co-trimoxazole (49\%), ciprofloxacin (23\%) and erythromycin (11\%) was noted in MSSA isolates. Among the erythromycin resistant strains of MSSA 15\% were clindamycin inducible. Co-resistance to a combination of amikacin with different classes of antibiotics is as follows: ampicillin with amikacin (6\%), co-amoxiclav with amikacin (4\%), ciprofloxacin with amikacin (1\%) and ceftriazone with amikacin (1\%). Co-resistance to ciprofloxacin and erythromycin was (6\%).

Four MSSA isolates were MDR (resistant to 3 different antibiotics ie, co-trimoxazole, ciprofloxacin and erythromycin) and two of the carriers of these isolates had reported history of hospitalization in the previous two weeks and both had received ceftriaxone during hospitalization.

No resistance was noted to vancomycin, linezolid or teicoplanin. Higher sensitivity was noted to clindamycin (94\%), chloramphenicol (87.5\%), doxycycline (82.7\%), amikacin (81.3\%) and erythromycin (76.6\%).

The antibiotic sensitivity pattern of 16 isolates of MRSA is shown in Figure 2. The MRSA isolates showed resistance to co-trimoxazole (75\%), doxycycline (44\%), ciprofloxacin (44\%), levofloxacin (31\%) and erythromycin (44\%). Among the erythromycin resistant strains of MRSA 35\% were clindamycin inducible. Co-resistance to ciprofloxacin and erythromycin (25\%), erythromycin 


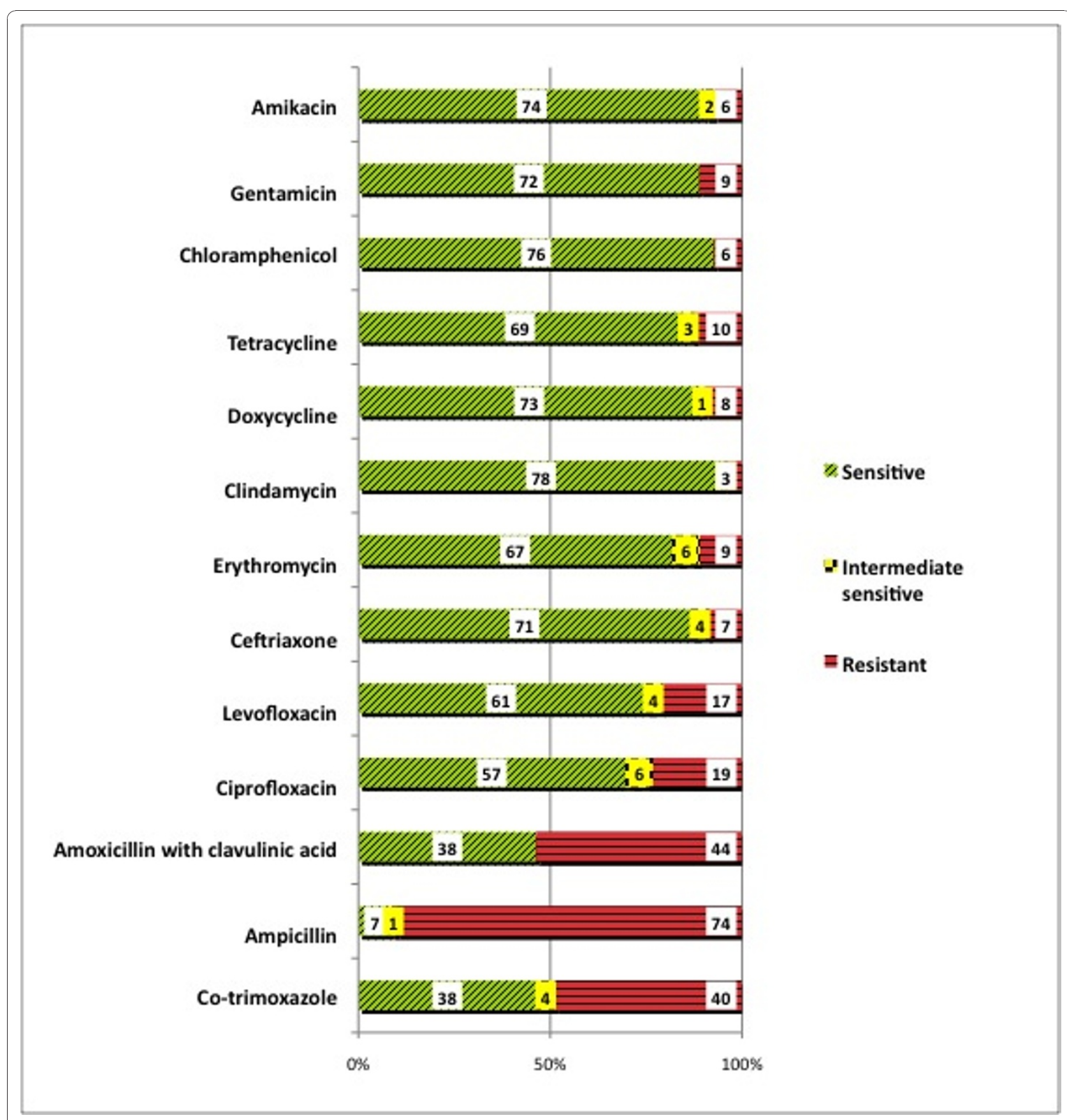

Figure 1 Antibiotic sensitivity patterns of 82 isolates of Methicillin susceptible Staphylococcus aureus (MSSA) in children from 1-59 months of age in Ujjain.

and amikacin (19\%), doxycycline and amikacin (12.5\%) ciprofloxacin and amikacin (12.5\%), levofloxacin and amikacin (12.5\%) doxycycline and levofloxacin (6\%), clindamycin and amikacin (6\%), was noticed.

Among the 16 MRSA isolates 3 (19\%) were MDR. Among the carriers of these isolates one child was hospitalized in the last two weeks and had received antibiotic co-amoxiclav during the stay.

\section{Discussion}

This is the first study from India reporting $S$. aureus nasal carriage rate in healthy children below 5 years. The study showed that $6.3 \%$ of healthy children below 5 years attending outpatient clinics of two hospitals in Ujjain carried $S$. aureus out of which $16.3 \%$ were MRSA. Ramana KV et al [10] reported a prevalence of $16 \%$ for $S$. aureus, 19\% of which were MRSA among school going 


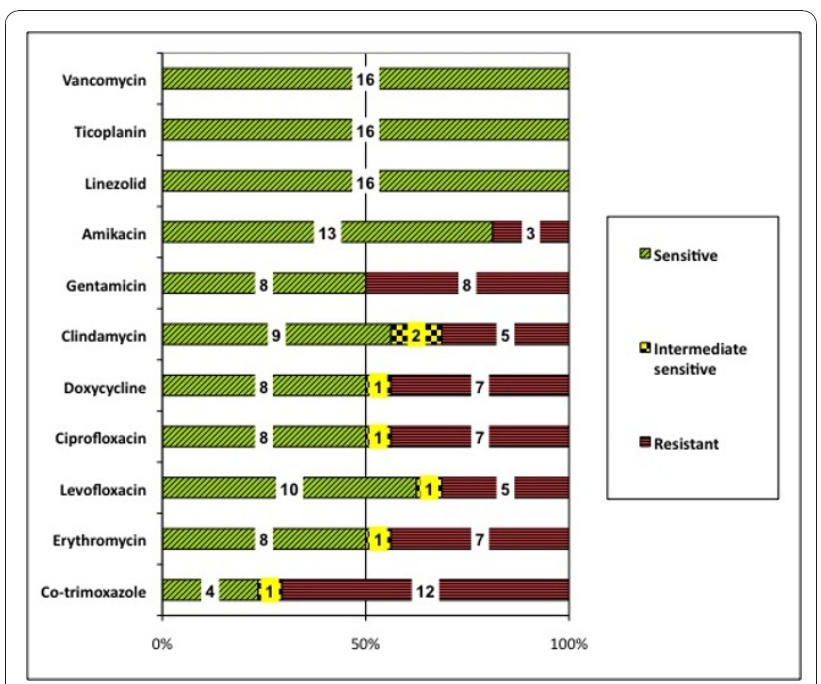

Figure 2 Antibiotic sensitivity patterns of 16 isolates of Methicillin resistant Staphylococcus aureus (MRSA) in children from 1-59 months of age in Ujjain.

children (5 to 15 years) in Narketpally, Andhra Pradesh, India. However, the factors associated with acquisition of $S$. aureus where not evaluated in that study. In another study of 489 school children (5 to 15 years of age) by Chatterjee SS et al [11] using enriched culture media and PCR assay for mecA gene, colonization was found in 256 (52.5\%) children. Out of these $3.9 \%$ were MRSA. They identified living in mud-thatch housing as factor associated with nasal carriage in their study.

The carrier rates of $S$. aureus and MRSA reported in different studies are shown in Table 2. It can be noted that $S$. aureus colonization is generally lower in resource poor countries and varies in the same community over time with increasing rates in the more recent studies. One possible explanation of high nasal carriage of $S$. aureus in resource rich countries could be low rates of exposure to antigens due to better personal hygiene leading to decreased clearing of pathogens in the tested patients [15].

The prevalence of colonization with $S$. aureus has previously been shown to be age dependent [2-4,16-18]. The prevalence varied across different age groups in our study with lower prevalence in the first six months of life although these differences were not statistically significant. The peak of colonization with a respiratory pathogen may be seen at 2-3 years of age [18]. During this age a lot of pathogens compete for colonization of the anterior nares; examples are pneumoccoci, Haemophilus influenzae, Moraxella catarrhalis and S. aureus. Bacterial interference, phenomenon by which colonization by one bacterial strain prevents colonization by another strain, plays an important role in establishing or eliminating one bacterial strain over another [15].
In our study the children attending school or anganwadi (Government of India run mother and child (0 to 6 years) services) were shown to have significantly higher prevalence of carriage. The finding is consistent with the fact that large family size with 10 or more members had higher carriage prevalence as compaired to families with less than or equal to 4 members. This might be due to poor hygiene and overcrowding. Recent studies have demonstrated the importance of close contacts within households [19] and with parents [20] in spread of $S$. aureus carriage among children residing in the same household. In the above two studies the children shared the genotype of $S$. aureus with one of the parents, more often the mother indicating the importance of close contact within the family.

Hospitalization in the recent past was not a factor significantly associated with nasal carriage in our study. However, hospitalization has been demonstrated by other studies [3,16,21-23] as a significant risk factor. Similarly, hospital visit is considered a risk factor [3] for acquiring $S$. aureus carriage however; in our study hospital visit was not identified as a statistically significant factor associated with nasal carriage.

In our study we did not find exposure to antibiotics in the past 2 weeks as an important factor associated with $S$. aureus carriage. However, in our study too, two of the four children carrying MDR isolate of MSSA and one of the three children carrying MDR MRSA isolates had reported history of hospitalization. Many of these children had received antibiotics in the last two weeks.

A meta-analysis by Costelloe et al [24] discussed the effect of antibiotic exposure on resistance over 12 months in MRSA isolated from skin abrasions. The authors reported a pooled OR of 1.04 with confidence interval crossing the null. But, the meta-analysis had only three studies included in it. Also, as in the present study, data on antibiotic exposure was by parental reports only, which was the case in two of the three studies included in the meta-analysis [24]. Antibiotic use is one of the most important determinants of antibiotic resistance [24]. A high antibiotic use rate is reflected by the fact that $26 \%$ of children enrolled in the study had received an antibiotic in the previous two weeks. Antibiotic stewardship programmes that promote judicious use of antibiotic are urgently needed and could prove to be more cost effective then targeted screening based on risk factors, isolation of the carriers and decolonization [24]. Simple hygiene measures like hand washing are effective in preventing spread of resistant organisms in the community. The importance of hygiene is exemplified in an intervention program in Swedish day care centres, which introduced alcohol-based hand washing for children. This intervention significantly reduced (by $12 \%$ points) children's absence from the day care [25]. 
Table 2 Carrier rates of S. aureus and MRSA reported in different studies

\begin{tabular}{|c|c|c|c|c|c|c|c|}
\hline Authors & $\begin{array}{l}\text { Year of } \\
\text { publication }\end{array}$ & Country & $\begin{array}{l}\text { Age group } \\
\text { included }\end{array}$ & $\begin{array}{l}\text { Study } \\
\text { setting }\end{array}$ & $\begin{array}{l}\text { Sample } \\
\text { size }\end{array}$ & $\begin{array}{l}\text { S. aureus nasal } \\
\text { carriage rate }\end{array}$ & $\begin{array}{l}\text { MRSA } \\
\text { carriage rate }\end{array}$ \\
\hline $\begin{array}{l}\text { Ramana KV } \\
\text { et al [10] }\end{array}$ & 2009 & India & 5-15 year & Schools & 392 & $16 \%$ & $\begin{array}{l}19 \% \text { of the } \\
\text { S. aureus samples }\end{array}$ \\
\hline $\begin{array}{l}\text { Chatterjee SS } \\
\text { et al [11] }\end{array}$ & 2009 & India & 5-15 year & Schools & 489 & $52.5 \%(P C R)$ & $3.89 \%$ \\
\hline $\begin{array}{l}\text { Ciftci H et al } \\
{[16]}\end{array}$ & 2007 & Turkey & 4-6 years & Schools & 1134 & $28.4 \%$ & $0.3 \%$ \\
\hline Ko KS et al [28] & 2008 & Korea & $1-11$ years & Hospital outpatients & 296 & 32.1 & $\begin{array}{l}18.9 \% \text { of the } \\
\text { S. aureus samples }\end{array}$ \\
\hline $\begin{array}{l}\text { Lamaro-Cardosa } \\
\text { J et al [21] }\end{array}$ & 2009 & Brazil & $\begin{array}{l}2 \text { months to } \\
5 \text { years }\end{array}$ & Day care centres & 1,192 & $31.1 \%$ & $1.2 \%$ \\
\hline $\begin{array}{l}\text { Lebon A et al } \\
{[22]}\end{array}$ & 2008 & Netherlands & $\begin{array}{l}1.5 \text { months and } \\
14 \text { months }\end{array}$ & $\begin{array}{l}\text { Community based } \\
\text { longitudinal study }\end{array}$ & 443 & $\begin{array}{l}12.9 \% \text { at } 1.5 \text { months and } \\
12.9 \% \text { at } 14 \text { months }\end{array}$ & Not reported \\
\hline $\begin{array}{l}\text { Lee GM et al } \\
{[23]}\end{array}$ & 2009 & $\begin{array}{l}\text { USA } \\
\text { (Massachusetts) }\end{array}$ & $\begin{array}{l}3 \text { months to less } \\
\text { than } 7 \text { years }\end{array}$ & Community & 1,968 & $\begin{array}{l}14.1 \text { in } 2003-4 \text { and } 14.6 \% \\
\text { in } 2006-7\end{array}$ & $\begin{array}{l}0.2 \% \text { in } 2003-4 \text { and } \\
0.9 \% \text { in } 2006-7\end{array}$ \\
\hline Lo WT et al [29] & 2007 & Taiwan & $\begin{array}{l}\text { Less than } \\
7 \text { years }\end{array}$ & Day care centres & 68 & $25 \%$ & $13.2 \%$ \\
\hline $\begin{array}{l}\text { Oguzkaya-Artan } \\
\text { M et al [30] }\end{array}$ & 2008 & Turkey & $0-6$ years & Primary care centre & 200 & $18 \%$ & $5.6 \%$ \\
\hline $\begin{array}{l}\text { Regev-Yochay } \\
\text { G et al [20] }\end{array}$ & 2009 & Israel & $0-40$ months & Primary care centre & 4,648 & $7.6 \%$ & Low (3 children) \\
\hline
\end{tabular}

Early in the global epidemic of MRSA there was a clear distinction in susceptibility pattern of CA-MRSA and hospital associated MRSA (HA-MRSA), with CAMRSA being susceptible to most antibiotics and typically highly sensitive to clindamycin [26]. Recent studies, however, demonstrate that the boundaries between these two entities are getting blurred [21,23,26]. This may be due to simultaneous horizontal transmission of multiple HA-MRSA strains in the community; indicating established transmission of HA-MRSA in the community for some time [27]. The S. aureus isolates in our study show high sensitivity to clindamycin but have high resistance to co-amoxiclav. This may represents a scenario of a late stage of spread in the community, albeit at a low rate [26,27].

In MRSA isolates resistance was seen to antibiotics that are important for empirically treating severe infections. These antibiotics include doxycycline (44\%), levofloxacin (31\%) and clindamycin (5\%). Resistance to levofloxacin and clindamycin is a cause of concern because of their therapeutic value in treating serious $S$. aureus infections in high-risk patients. However, it is important to note that the present results are of carriage state and not clinical infections.

Our study has limitations; firstly, we did not use an enriched media for culture of $S$. aureus, which might have reduced our detection rates. Secondly, we did not measure the minimum inhibitory concentration (MIC), which is the recommended method especially for glycopeptide antibiotics. However, we did not notice resistance to gycopeptides in our study. Also, we did not do confirm
MRSA status by doing $m e c A$ gene due to financial constrains. Thirdly, our study is an observational study conducted in hospital setting although with healthy children from the community. A community based cohort design with sampling of a given child at various ages would have identified persistent carriage (carriage over time), which is more important source for community spread.

\section{Conclusions}

This is the first study among Indian children below five years of age studying the prevalence of nasal carriage and showed a prevalence of $6.3 \%$ for S. aureus $16.3 \%$ of which were MRSA. The study shows that attending preschool or school and living in a large family was associated with nasal carriage of $S$. aureus. More studies with cohort design are needed to accurately assess the epidemiology of $S$. aureus nasal carriage in various geographical locations.

\section{Acknowledgements}

We thank all the participating physicians and patients for their co-operation during data collection and Dr VK Mahadik, Medical Director, RD Gardi Medical College, for administrative support during the project. This project is funded by the VR (the Swedish Research Council) and the Asia link. We thank the Erasmus Mundus External Cooperation Window lot 15 and Swedish Research School for Global Health for scholarships to AP for his doctoral studies.

\section{Author details}

${ }^{1}$ Division of Global Health (IHCAR), Department of Public Health Sciences, Nobels väg 9, Karolinska Institutet, Stockholm, 17177, Sweden. ²Department of Pediatrics, R.D. Gardi Medical College, 456010, Ujjain, India. ${ }^{3}$ Department of Microbiology, R.D. Gardi Medical College, 456010, Ujjain, India.

${ }^{4}$ Department of Pharmacology, R.D. Gardi Medical College, 456010, Ujjain, 
India. ${ }^{5}$ Nordic School of Public Health, Göteborg, Sweden. ${ }^{6}$ St Johns Research Institute, Bangalore, India.

\section{Authors' contributions}

$A P, Y M, R V I, M S, B E, R M$ and CSL participated in the conception and design of the study and revising the paper critically for substantial intellectual content. AP was responsible for the data collection, performed the data analysis and drafted the manuscript. YM, RVI and BS were responsible for laboratory testing. BE contributed to the statistical analysis. All authors read and approved the final manuscript

\section{Competing interests}

The authors declare that they have no competing interest.

Received: 16 June 2010 Accepted: 29 December 2010

Published: 29 December 2010

\section{References}

1. Lowy FD: Staphylococcus aureus infections. N Engl J Med 1998, 339(8):520-532.

2. Peacock SJ, Justice A, Griffiths D, de Silva GD, Kantzanou MN, Crook D, Sleeman K, Day NP: Determinants of acquisition and carriage of Staphylococcus aureus in infancy. J Clin Microbiol 2003, 41(12):5718-5725.

3. Kluytmans J, van Belkum A, Verbrugh H: Nasal carriage of Staphylococcus aureus: epidemiology, underlying mechanisms, and associated risks. Clin Microbiol Rev 1997, 10(3):505-520.

4. Grundmann H, Aires-de-Sousa M, Boyce J, Tiemersma E: Emergence and resurgence of meticillin-resistant Staphylococcus aureus as a publichealth threat. Lancet 2006, 368(9538):874-885.

5. Anupurba S, Sen MR, Nath G, Sharma BM, Gulati AK, Mohapatra TM: Prevalence of methicillin resistant staphylococcus aureus in a tertiary referral hospital in eastern Uttar Pradesh. Indian J Med Microbiol 2003, 21(1):49-51.

6. Majumder D, Bordoloi JS, Phukan AC, Mahanta J: Antimicrobial susceptibility pattern among methicillin resistant staphylococcus isolates in Assam. Indian J Med Microbiol 2001, 19(3):138-140.

7. Rajaduraipandi K, Mani KR, Panneerselvam K, Mani M, Bhaskar M, Manikandan P: Prevalence and antimicrobial susceptibility pattern of methicillin resistant Staphylococcus aureus: a multicentre study. Indian J Med Microbiol 2006, 24(1):34-38

8. Saxena S, Singh K, Talwar V: Methicillin-resistant Staphylococcus aureus prevalence in community in the east Delhi area. Jpn J Infect Dis 2003, 56(2):54-56.

9. Chacko J, Kuruvila M, Bhat GK: Factors affecting the nasal carriage of methicillin-resistant Staphylococcus aureus in human immunodeficiency virus-infected patients. Indian Journal of Medical Microbiology 2009, 27(2):146-148.

10. Ramana KV, Mohanty SK, Wilson CG: Staphylococcus aureus colonization of anterior nares of school going children. Indian J Pediatr 2009, 76(8):813-816.

11. Chatterjee SS, Ray P, Aggarwal A, Das A, Sharma M: A community-based study on nasal carriage of Staphylococcus aureus. Indian J Med Res 2009, 130(6):742-748.

12. District fact sheets Madhya Pradesh Human Development Report MPHDR. 2002, 138-319 [http://www.mp.gov.in/difmp/mphdr\% 5CDistFactSheets_E_2002.pdf], (18/12/2010 date last accessed).

13. Cinical and Laboratory Standards Institute: Performance Standard for Antimicrobial Disk Susceptibility Testing. 16th Informational Supplement. M100-S16. Wayne, Pa 2006

14. Fiebelkorn KR, Crawford SA, McElmeel ML, Jorgensen JH: Practical disk diffusion method for detection of inducible clindamycin resistance in Staphylococcus aureus and coagulase-negative staphylococci. J Clin Microbiol 2003, 41(10):4740-4744.

15. Sivaraman K, Venkataraman N, Cole AM: Staphylococcus aureus nasal carriage and its contributing factors. Future Microbiol 2009, 4:999-1008.

16. Ciftci IH, Koken R, Bukulmez A, Ozdemir M, Safak B, Cetinkaya Z: Nasal carriage of Staphylococcus aureus in 4-6 age groups in healthy children in Afyonkarahisar, Turkey. Acta Paediatr 2007, 96(7):1043-1046.

17. Huang YC, Ho CF, Chen CJ, Su LH, Lin TY: Nasal carriage of methicillinresistant Staphylococcus aureus in household contacts of children with community-acquired diseases in Taiwan. Pediatr Infect Dis J 2007, 26(11):1066-1068.

18. Bogaert D, van Belkum A, Sluijter M, Luijendijk A, de Groot R, Rumke HC, Verbrugh HA, Hermans PW: Colonisation by Streptococcus pneumoniae and Staphylococcus aureus in healthy children. Lancet 2004, 363(9424):1871-1872.

19. Miller $M$, Cook HA, Furuya EY, Bhat $M$, Lee $M H$, Vavagiakis $P$, Visintainer $P$, Vasquez G, Larson E, Lowy FD: Staphylococcus aureus in the community: colonization versus infection. PLoS One 2009, 4(8):e6708.

20. Regev-Yochay G, Raz M, Carmeli Y, Shainberg B, Navon-Venezia S, Pinco E, Leavitt A, Keller N, Rahav G, Malley R, et al: Parental Staphylococcus aureus carriage is associated with staphylococcal carriage in young children. Pediatr Infect Dis J 2009, 28(11):960-965.

21. Lamaro-Cardoso J, de Lencastre H, Kipnis A, Pimenta FC, Oliveira LSC Oliveira RM, Nouer SS, Aires-de-Sousa M, Milheirico C, Andrade ALS: Molecular Epidemiology and Risk Factors for Nasal Carriage of Staphylococcus aureus and Methicillin-Resistant S. aureus in Infants Attending Day Care Centers in Brazil. J Clin Microbiol 2009, 47(12):3991-3997.

22. Lebon A, Labout JAM, Verbrugh HA, Jaddoe WW, Hofman A, van Wamel W, Moll HA, van Belkum A: Dynamics and Determinants of Staphylococcus aureus Carriage in Infancy: the Generation R Study. J Clin Microbiol 2008, 46(10):3517-3521.

23. Lee GM, Huang SS, Rifas-Shiman SL, Hinrichsen VL, Pelton SI, Kleinman K, Hanage WP, Lipsitch M, McAdam AJ, Finkelstein JA: Epidemiology and risk factors for Staphylococcus aureus colonization in children in the postPCV7 era. BMC Infect Dis 2009, 9:110.

24. Costelloe C, Metcalfe C, Lovering A, Mant D, Hay AD: Effect of antibiotic prescribing in primary care on antimicrobial resistance in individual patients: systematic review and meta-analysis. BMJ 2010, 340:c2096.

25. Lennell A, Kuhlmann-Berenzon S, Geli P, Hedin K, Petersson C, Cars O, Mannerquist K, Burman LG, Fredlund $\mathrm{H}$ : Alcohol-based hand-disinfection reduced children's absence from Swedish day care centers. Acta Paediatr 2008, 97(12):1672-1680.

26. Bartlett JG: Methicillin-resistant Staphylococcus aureus infections. Top HIV Med 2008, 16(5):151-155.

27. Salgado CD, Farr BM, Calfee DP: Community-acquired methicillin-resistant Staphylococcus aureus: a meta-analysis of prevalence and risk factors. Clin Infect Dis 2003, 36(2):131-139.

28. Ko KS, Lee JY, Baek JY, Peck KR, Rhee JY, Kwon KT, Heo ST, Ahn KM, Song $\mathrm{JH}$ : Characterization of Staphylococcus aureus nasal carriage from children attending an outpatient clinic in Seoul, Korea. Microb Drug Resist 2008, 14(1):37-44.

29. Lo WT, Lin WJ, Tseng MH, Lu JJ, Lee SY, Chu ML, Wang CC: Nasal carriage of a single clone of community-acquired methicillin-resistant Staphylococcus aureus among kindergarten attendees in northern Taiwan. BMC Infect Dis 2007, 7:51

30. Oguzkaya-Artan M, Baykan Z, Artan C: Nasal carriage of Staphylococcus aureus in healthy preschool children. Jpn J Infect Dis 2008, 61(1):70-72.

\section{Pre-publication history}

The pre-publication history for this paper can be accessed here: http://www.biomedcentral.com/1471-2431/10/100/prepub

doi:10.1186/1471-2431-10-100

Cite this article as: Pathak et al: Nasal Carriage and Antimicrobial Susceptibility of Staphylococcus aureus in healthy preschool children in Ujjain, India. BMC Pediatrics 2010 10:100. 